\title{
Split-dose bowel preparation versus water exchange and adenoma detection rate: have we arrived there yet?
}

\author{
Felix W. Leung \\ David Geffen School of Medicine at UCLA, Los Angeles, CA, United States
}

Inadequate bowel preparation in screening colonoscopy interferes with adenoma detection, reduces the adenoma detection rate (ADR: the proportion of patients with at least one adenoma of any size), and increases the risk of interval colorectal cancers (those diagnosed within 3-5 years of the index screening examination). Studies with split-dose bowel preparation focused primarily on achieving adequacy of bowel cleanliness in traditional air-insufflation (AI) colonoscopy. Despite advances, split-dose preparation has limitations. What are these limitations and how have they been addressed?

The current issue of Annals of Gastroenterology includes a report describing a cross-sectional, dual-center study that used a multilingual survey to collect patient-reported demographic, medical, socioeconomic, and tolerability data from patients undergoing outpatient colonoscopy [1]. Of the 1023 patients who returned questionnaires, $342(33.4 \%)$ had completed single-dose and $681(66.6 \%)$ split-dose preparation. Of the patients surveyed, 39\% were Hispanic, $50 \%$ had Medicaid or no insurance, and $34 \%$ had self-reported limited English proficiency. Patients who underwent split-dose preparation were significantly more likely to report a tolerable preparation, with less severe symptoms, than patients who underwent single-dose preparation. Multiple logistic regression revealed that male sex and instructions in a preferred language were associated with tolerability of the single-dose preparation, while male sex and concerns about medications were associated with tolerability of the split-dose preparation [1]. The study appeared to confirm a suboptimal patient attitude towards the split-dose regimen [2]. An earlier, but quite recent, report [2] described preferences in 1447 patients: $61.7 \%$ and $38.3 \%$ chose the split-dose and day-before regimens, respectively. A linear correlation was observed between the time of colonoscopy appointments and split-dose uptake, from 27.3\% among patients with an 8:00 appointment to $96 \%$ in those scheduled

Gastroenterology, Medicine, Sepulveda Ambulatory Care Center, North Hills; Veterans Affairs Greater Los Angeles Healthcare System and David Geffen School of Medicine at UCLA, Los Angeles, CA, United States

\section{Conflict of Interest: None}

Correspondence to: Felix W. Leung, MD, 111G, Gastroenterology, Sepulveda Ambulatory Care Center, Veterans Affairs Greater Los Angeles Healthcare System, 16111 Plummer Street, North Hill, CA, 91343, USA, e-mail: felix.leung@va.gov

Received 7 February 2018; accepted 22 February 2018;

published online 18 April 2018

DOI: https://doi.org/10.20524/aog.2018.0257 for 14:00 $\left(\mathrm{P}<0.001, \mathrm{c}^{2}\right.$ for linear trend). On multivariate analysis, a colonoscopy appointment before 10:00 (odds ratio [OR] 0.14, 95\% confidence interval [CI] 0.11-0.18), travel time to endoscopy service $>1$ h (OR $0.55,95 \%$ CI $0.38-0.79$ ), low education level (OR 0.72, 95\%CI 0.54-0.96) and female sex (OR $0.74,95 \%$ CI $0.58-0.95$ ) were inversely correlated with the uptake of split-dose [2].

Approaches addressing the improved performance of splitdose preparation were reported. One randomized controlled trial (RCT) showed that, after a 3-day low-residue diet and oral bisacodyl before colonoscopy, colon cleansing with 4-L split-dose polyethylene glycol (PEG) was superior to 2-L split-dose PEG + ascorbic acid in patients with previous inadequate cleansing [3]. A meta-analysis of RCTs showed that a counseling session with patients before colonoscopy ensured better bowel preparation. However, the evidence was insufficient to assess avoidance of a repeat colonoscopy or any improvement in polyp detection rate [4]. Wang et al [5] described the effect of changing from a single- to a split-dose preparation on colonoscopy quality measures in a retrospective cohort study based on electronic medical record data including quality indicators. The results included 1602 colonoscopies in the single-dose group and 1061 colonoscopies in the splitdose group. The Boston Bowel Preparation Scale (BBPS) score was significantly better in the split-dose group (8.64 vs. $8.25, \mathrm{P}<0.0001$ ), whereas the rate for recommending an early repeat examination because of inadequate bowel preparation was significantly lower in the split-dose group $(3.9 \%$ vs. $8.9 \%, \mathrm{P}<0.0001)$. These observation have important clinical implications for performance, costs, and patient experience, and provide evidence to support the use of split-dose preparation. There was no significant difference in ADR ( $40.7 \%$ vs. $40.5 \%$, $\mathrm{P}=0.92$ ), suggesting an ADR threshold over which improved bowel preparation would have little impact [5].

Addressing the lack of ADR improvement, a recent RCT reported for the first time that split-dose bowel preparation significantly improved bowel cleanliness and ADR [6]. On perpatient analysis, the proportion of subjects with at least one adenoma was significantly higher with split- than single-dose $(183 / 345,53.0 \%$ vs. $141 / 345,40.9 \%$, relative risk $1.22,95 \% \mathrm{CI}$ 1.03-1.46) [6]. Another report in the Annals of Gastroenterology described an analysis of segmental BBPS scores and ADR [7]. The association of segmental and overall ADR and serrated polyp detection rate (SDR) with segmental and total BBPS scores was examined. All screening colonoscopies in outpatients with documented BBPS scores from January to December 2013 were reviewed retrospectively. The results included 1991 colonoscopies. The overall ADR was 37.5\% (95\%CI 35.3-39.6). 
Table 1 Comparison of WE and AI in randomized controlled trials

\begin{tabular}{|c|c|c|c|c|}
\hline Reference & Parameter & WE & AI & $\mathrm{P}$ \\
\hline \multirow[t]{3}{*}{ Hsieh et al, 2017 [11] } & Number of subjects & 217 & 217 & \\
\hline & Overall BBPS score* & $7.1 \pm 1.3$ & $6.2 \pm 1.1$ & $<0.0001$ \\
\hline & Overall ADR by intention-to-treat analysis & $49.8 \%$ & $37.8 \%$ & 0.016 \\
\hline \multirow[t]{3}{*}{ Cadoni et al, 2017 [12] } & Number of subjects & 408 & 408 & \\
\hline & Overall BBPS score $\dagger$ & $9.0(7.0-9.0)$ & $8.0(6.0-9.0)$ & $<0.001$ \\
\hline & Overall ADR & $49.3 \%$ & $40.4 \%$ & 0.03 \\
\hline \multirow[t]{3}{*}{ Jia et al, 2017 [14] } & Number of subjects & 1653 & 1650 & \\
\hline & Overall $\mathrm{BBPS}^{*}$ score & $7.3 \pm 1.6$ & $7.0 \pm 2.3$ & $<0.001$ \\
\hline & Overall ADR & $18.3 \%$ & $13.4 \%$ & $<0.001$ \\
\hline
\end{tabular}

${ }^{*}$ Mean \pm SD; $\uparrow$ Median (interquartile range) P-values are based on analyses using relative risk or $\chi^{2}$

$A D R$, adenoma detection rate; BBPS, Boston Bowel Preparation Scale; WE, water exchange; AI, air insufflation

Table 2 Pooled data comparing WE, WI, and AI [15]

\begin{tabular}{|c|c|c|c|c|c|c|c|}
\hline \multirow[t]{2}{*}{ Parameter } & \multirow[t]{2}{*}{ WE } & \multirow[t]{2}{*}{ WI } & \multirow[t]{2}{*}{ AI } & \multicolumn{4}{|c|}{ P-value } \\
\hline & & & & Overall & WI vs. AI & WE vs. AI & WE vs. WI \\
\hline Number of subjects & 625 & 625 & 625 & & & & \\
\hline Overall BBPS* score & $7.6(1.5)$ & $7.2(1.5)$ & $7.0(1.6)$ & $<0.001$ & 0.224 & $<0.001$ & $<0.001$ \\
\hline ADR, n (\%) & $310(49.6)$ & $265(42.4)$ & $247(39.5)$ & 0.001 & 0.903 & 0.001 & 0.033 \\
\hline
\end{tabular}

${ }^{\star}$ Mean \pm SD P-values are based on analyses using relative risk or $\chi^{2}$

$A D R$, adenoma detection rate; BBPS, Boston Bowel Preparation Scale; WE, water exchange; WI, water immersion; AI, air insufflation

There was a significant difference in the overall ADR and SDR across all bowel category groups, with total BBPS scores of 8 and 9 having lower detection rates than scores of 5,6 and 7. As the quality of bowel preparation increased, there was a statistically significant decrease in the $\mathrm{ADR}$ of the right colon $(\mathrm{P}=0.04$; OR $0.79,95 \%$ CI 0.65-0.95), while in the left colon there was a statistically significant decrease in the SDR $(\mathrm{P}=0.019$; OR 0.78, 95\%CI 0.65-0.92). A possible explanation for this discrepancy might be the longer and better visualization of the mucosa when cleansing and suctioning were necessary [7].

Suboptimal bowel cleanliness could result from noncompliance and a prospective study specifically showed 1 in 7 did not comply with a split-dose bowel regimen [8]. One retrospective report in patients who were examined using the traditional AI method discussed intra-procedural bowel cleansing during withdrawal as a possible solution for those with inadequate cleanliness despite split-dose preparation [9]. The practice could reduce the need for early repeat colonoscopy, thereby reducing costs and patient and endoscopist time and inconvenience, while potentially improving outcomes [9]. Water immersion (WI) [10-12], which used water infusion to aid insertion in traditional AI colonoscopy, also left removal of most of the infused water and residual debris to the withdrawal phase. The practice of withdrawal cleaning consumed time that otherwise could have been devoted to examining for adenomas.

Cleaning during insertion was an integral component of water exchange (WE) colonoscopy [11-15]. WE was modified from WI [10] by the exclusion of air and the addition of removal of water and residual debris during insertion [13]. The added maneuvers minimized distension of the colon lumen to reduce insertion pain in unsedated patients, and provided salvage cleaning to optimize bowel cleanliness. Bowel cleansing during insertion was deemed "cumbersome and time-consuming" if considerable residual feces were present. The improved cleanliness with split-dose bowel preparation facilitated salvage cleaning during insertion with WE. The net result reduced the need to perform cleaning during withdrawal. Compared with traditional AI colonoscopy in patients purged with a split-dose regimen, WE has been associated with a significant increase in BBPS scores and ADR (Table 1). Moreover, pooled RCT data $[11,12]$ showed that WE also significantly increased ADR in addition to significantly improving bowel cleanliness compared with WI (Table 2) [15]. These RCT data support the hypothesis that salvage cleaning during colonoscope insertion by WE is efficacious in enhancing bowel cleanliness and adenoma yield, even after split-dose preparation.

Taken together, there are impediments to achieving an optimal result from split-dose preparation [1,2,8,9]. Modification of the bowel cleansing regimen [3], patient education [4], and intra-procedure cleansing performed during withdrawal $[9,11,12]$ or during insertion [11-14] are important measures for overcoming the limitations and improving the outcomes of split-dose preparation. To date, only WE with insertion salvage cleaning has been associated with both significantly better bowel cleanliness and a significantly greater ADR, compared with AI [11,12,14] and WI [15] colonoscopy. 
The improvement in the surrogate marker for colorectal cancer, namely ADR, suggests WE is the ideal screening colonoscopy method when used with split-dose bowel preparation. Whether the increased ADR by WE will eventually result in a decrease in the occurrence of interval colorectal cancer remains to be studied further.

\section{Acknowledgment}

Supported in part by VA Medical research funds.

\section{References}

1. Perreault G, Goodman A, Larion S, et al. Split versus single dose preparation tolerability in a multi-ethnic population: decreased side effects but greater social barriers. Ann Gastroenterol 2018;31:356-364.

2. Radaelli F, Paggi S, Repici A, et al. Barriers against split-dose bowel preparation for colonoscopy. Gut 2017;66:1428-1433.

3. Gimeno-García AZ, Hernandez G, Aldea A, et al. Comparison of two intensive bowel cleansing regimens in patients with previous poor bowel preparation: a randomized controlled study. Am J Gastroenterol 2017;112:951-958.

4. Chang CW, Shih SC, Wang HY, et al. Meta-analysis: The effect of patient education on bowel preparation for colonoscopy. Endosc Int Open 2015;3:E646-E652.

5. Wang L, Sprung BS, DeCross AJ, et al. Split-dose bowel preparation reduces the need for early repeat colonoscopy without improving adenoma detection rate. Dig Dis Sci 2018;63:1320-1326.

6. Radaelli F, Paggi S, Hassan C, et al. Split-dose preparation for colonoscopy increases adenoma detection rate: a randomised controlled trial in an organised screening programme. Gut 2017;66:270-277.

7. Adike A, Buras M, Gurudu S, et al. Is the level of cleanliness using segmental Boston bowel preparation scale associated with a higher adenoma detection rate? Ann Gastroenterol 2018;31:217-223.

8. Menees SB, Kim HM, Wren P, et al. Patient compliance and suboptimal bowel preparation with split-dose bowel regimen in average-risk screening colonoscopy. Gastrointest Endosc 2014;79:811-820.

9. Oh CH, Lee CK, Kim JW, Shim JJ, Jang JY. Suboptimal bowel preparation significantly impairs colonoscopic detection of nonpolypoid colorectal neoplasms. Dig Dis Sci 2015;60:2294-2303.

10. Falchuk ZM, Griffin PH. A technique to facilitate colonoscopy in areas of severe diverticular disease. N Engl J Med 1984;310:598.

11. Hsieh YH, Tseng CW, Hu CT, Koo M, Leung FW. Prospective multicenter randomized controlled trial comparing adenoma detection rateincolonoscopyusing waterexchange, waterimmersion, and air insufflation. Gastrointest Endosc 2017;86:192-201.

12. Cadoni S, Falt P, Rondonotti E, et al. Water exchange for screening colonoscopy increases adenoma detection rate: a multicenter, double-blinded, randomized controlled trial. Endoscopy 2017;49:456-467.

13. Leung FW, Harker JO, Jackson G, et al. A proof-of-principle, prospective, randomized, controlled trial demonstrating improved outcomes in scheduled unsedated colonoscopy by the water method. Gastrointest Endosc 2010;72:693-700.

14. Jia H, Pan Y, Guo X, et al. Water exchange method significantly improves adenoma detection rate: a multicenter, randomized controlled trial. Am J Gastroenterol 2017;112:568-576.

15. Leung FW, Koo M, Cadoni S, et al. Water exchange produces significantly higher adenoma detection rate than water immersion: Pooled data from 2 multisite randomized controlled trials. J Clin Gastroenterol 2018; 2018 Mar 2 [Epub ahead of print] doi: 10.1097/ MCG.0000000000001012. 